\title{
Diuretic based therapy reduced CV mortality in older patients with isolated systolic hypertension and diabetes
}

Kostis JB, Wilson AC, Freudenberger RS, et al. Long-term effect of diuretic-based therapy on fatal outcomes in subjects with isolated systolic hypertension with and without diabetes. Am J Cardiol 2005;95:29-35.

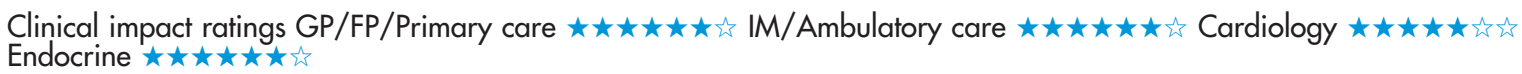

In older patients with isolated systolic hypertension (ISH) with or without diabetes, what is the long term effectiveness of a diuretic based, stepped care antihypertensive therapy compared with placebo?

\section{METHODS}

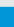

Design: randomised placebo controlled trial (Systolic

Hypertension in the Elderly Program [SHEP]).

Allocation: concealed.*

Blinding: blinded \{clinicians, patients, data collectors, outcome assessors, and data analysts* $\} \dagger$

$\sum\langle$

Follow-up period: median 14.3 years.

Setting: $\{16$ clinical centres in the US $\}$ †.

Patients: 4736 patients $\geqslant 60$ years of age who had ISH (systolic blood pressure [BP] 160 to $219 \mathrm{~mm} \mathrm{Hg}$ and diastolic BP $<90 \mathrm{~mm}$ $\mathrm{Hg})$. Patients with type 1 diabetes or those who required diuretic therapy were excluded.

D Intervention: stepped care therapy with chlorthalidone, 12.5 to $25.0 \mathrm{mg} /$ day $(\mathrm{n}=2363)$ or placebo $(\mathrm{n}=369)$ to achieve a systolic BP decrease of $\geqslant 20 \mathrm{~mm} \mathrm{Hg}$ to $<160 \mathrm{~mm} \mathrm{Hg}$. If the goal $\mathrm{BP}$ was not reached, atenolol or matching placebo was added.

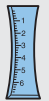

Outcomes: all cause and cardiovascular (CV) mortality.

Patient follow up: 4732 patients (>99\%) (mean age 72 y, 58\% women, $17 \%$ diabetes). Analysis was by intention to treat.

*See glossary.

†Information provided by author.

\section{MAIN RESULTS}

At the end of the extended follow up, the stepped care and placebo groups did not differ for all cause mortality (table). Fewer patients who received stepped care died from CV causes than did those who

For correspondence: Dr J B Kostis, UMDNJ-Robert Wood Johnson Medical School, New Brunswick, NJ, USA. kostis@umdnj.edu

Sources of funding: National Heart, Lung and Blood Institute; National Institute on Aging; Robert Wood Johnson Foundation.

Stepped care with chlorthalidone $v$ placebo for older patients with isolated systolic hypertension*

\begin{tabular}{lllll}
\hline $\begin{array}{l}\text { Outcomes at median } \\
\text { 14.3 years }\end{array}$ & $\begin{array}{l}\text { Stepped } \\
\text { care }\end{array}$ & Placebo & RRR (CI) & NNT (CI) \\
\hline All cause mortality & $41 \%$ & $43 \%$ & $\begin{array}{l}5.9 \% \\
(-0.7 \text { to } 12)\end{array}$ & $\begin{array}{l}\text { Not } \\
\text { significant } \\
36\end{array}$ \\
$\begin{array}{l}\text { Cardiovascular } \\
\text { mortality }\end{array}$ & $19 \%$ & $22 \%$ & $\begin{array}{l}13 \% \\
(2.5 \text { to } 23)\end{array}$ & (21 to 186) \\
\hline
\end{tabular}

*Abbreviations defined in glossary; RRR, NNT, and Cl calculated from hazards ratios in article. received placebo (table). During follow up, diabetes developed in 258 patients $(13 \%)$ in the stepped care group and in 169 patients $(8.7 \%)$ in the placebo group $(\mathrm{p}<0.001)$. Patients with diabetes at baseline had higher mortality than did those without diabetes at baseline in both the stepped care and placebo groups. Patients who developed diabetes during follow up had higher mortality than did those who did not develop diabetes in the placebo group (47\% v 40\%, hazard ratio [HR] $1.3,95 \%$ CI 1.1 to 1.7 ) but not in the stepped care group ( $39 \%$ \% $40 \%$, HR 1.2, CI 0.9 to 1.4). A similar pattern was seen for CV mortality. Patients who had diabetes at baseline or who developed diabetes during follow up and received stepped care had lower all cause ( $44 \%$ v 52\%, HR 0.8 , CI 0.7 to 0.95$)$ and CV (20\% v 29\%, HR 0.7, CI 0.5 to 0.8 ) mortality than did those who received placebo.

\section{CONCLUSIONS}

In older patients with isolated systolic hypertension, diuretic based, stepped care antihypertensive therapy reduced long term cardiovascular mortality. Patients who had diabetes at baseline or who developed diabetes during follow up and received stepped care had lower mortality than did those who received placebo.

Abstract and commentary also appear in ACP Journal Club.

\section{Commentary}

7 he study by Kostis et al reports the long term effects of diuretic based therapy in the SHEP trial. During the extended 10 year follow up, diuretic based therapy was associated with a lower rate of CV mortality, which was not observed during the 4.3 year double blind phase of the study. These results add more support to the JNC VII recommendation to use thiazide type diuretics as the initial therapy for uncomplicated hypertension.

It is clear from recent, large hypertension trials that several newer classes of drugs, including angiotensin converting enzyme inhibitors, angiotensin receptor blockers, and calcium channel blockers, reduce the complications of hypertension and can be used as first line therapy, but diuretics are as effective and cost less.' The use of diuretics as first line therapy for uncomplicated hypertension was shown to result in substantial cost savings. ${ }^{2}$

The uncontrolled nature of the extended follow up period for this study is its most important limitation. The analysis is based on a conservative assumption that after the double blind phase of the SHEP trial, most patients in the diuretic based therapy group continued diuretic therapy, whereas a smaller proportion of those randomised to placebo initiated diuretic based therapy.

During the double blind phase of the SHEP trial, mean systolic and diastolic BP were lower in the chlorthalidone group by $11.1 \mathrm{~mm} \mathrm{Hg}$ and $3.4 \mathrm{~mm} \mathrm{Hg}$, respectively, which could explain the better long term outcomes associated with chlorthalidone. Additional support for this explanation comes from the recently published VALUE trial in which amlodipine was superior to valsartan in BP control and in preventing myocardial infarction. ${ }^{3}$ Both SHEP and VALUE suggest that the degree of $\mathrm{BP}$ control is the most important predictor of favourable CV outcomes regardless of the antihypertensive agent used.

Abdullah Alkhenizan, MD, DCEpid King Faisal Specialist Hospital and Research Center Riyadh, Saudi Arabia

1 Psaty BM, Lumley T, Furberg CD, et al. JAMA 2003;289:2534-44.

2 Fischer MA, Avorn J. JAMA 2004;291:1850-6.

3 Julius S, Kieldsen SE, Weber M, et al. Lancet 2004;363:2022-31. 